\title{
You beta block: or not?
}

\section{Gilliland}

Department of Anaesthesiology, Chris Hani Baragwanath Academic Hospital, University of the Witwatersrand, South Africa Corresponding author, email: lizilg@gmail.com

\section{Summary}

$\beta$-blockers bind selectively to beta-adrenergic receptors and interfere with catecholamines provoking $\beta$-responses on the heart and smooth muscles of the airways and blood vessels. ${ }^{1}$

To block or not to block.

Keywords: $\beta$-blockers, beta-adrenergic receptors, heart, smooth muscles, airways, blood vessels

\section{What we do know}

Continue $\beta$-blockers in the perioperative period in patients who are taking it chronically. ${ }^{2-4}$

Consistent and clear associations exist between beta-blocker administration and adverse outcomes, such as bradycardia, hypotension and stroke. ${ }^{3,4}$

$\beta$-blocker therapy in high doses with no titration plan or sideeffect monitoring, should not be started on the day of surgery. ${ }^{3,4}$

\section{What we think we know}

Preoperative use of $\beta$-blockers was associated with a reduction in cardiac events, but data is lacking to support the effectiveness of preoperative administration of $\beta$-blockers to reduce risk of surgical death. ${ }^{4}$

Patients at high risk with serious comorbidities, such as heart failure, may benefit from $\beta$-blocker therapy, whereas low-risk patients (uncomplicated hypertension) may be at increased risk with $\beta$-blocker therapy. ${ }^{2}$

It may be reasonable to begin perioperative $\beta$-blockers in: ${ }^{4}$

- Patients with intermediate or high-risk myocardial ischaemia noted in preoperative risk stratification tests.

- Patients with three or more revised cardiac risk index (RCRI) risk factors (diabetes mellitus, congestive heart failure, coronary artery disease, renal insufficiency, cerebrovascular accident).

It is reasonable for the management of $\beta$-blockers after surgery to be guided by clinical circumstances. ${ }^{4}$

\section{What we don't know}

Whether gradual preoperative withdrawal of $\beta$-blocker therapy in the lowest risk patients might improve outcomes. ${ }^{2}$

\section{Receptor overview}

The heart contains a $70 / 30$ ratio of $\beta_{1} / \beta_{2}$ receptors. $\beta_{1}$ receptors are also found in the kidneys. $\beta_{2}$ receptors are also located in the bronchi, peripheral smooth muscle, liver, pancreas and in skeletal muscle. $\beta_{3}$ receptors are mainly found in adipose tissue. ${ }^{5}$

Stimulation of the $\beta$ receptor results in activation of adenyl cyclase through the action of the $\mathrm{G}_{\mathrm{s}} \mathrm{G}$-proteins, catalysing the formation of cyclic adenosine monophosphate (cAMP) which then activates protein kinase $A$. $\beta_{2}$ receptors can also couple with $\mathrm{G}_{\mathrm{i}}$ leading to inhibition of the adenyl cyclase system. ${ }^{6}$

\section{Pharmacodynamics}

$\beta$-blockers competitively antagonise adrenergic stimulation of the $\beta$-adrenoreceptor. They are also called sympatholytics. Differing abilities include preferential binding to $\beta_{1}$ receptors rendering them cardioselective, antagonist activity towards $\beta$ receptors and the presence/absence of intrinsic sympathomimetic activity (ISA). ${ }^{5}$

- Cardioselectivity is dose dependant. At high doses agents become non-selective.

- ISA relates to partial agonist (thus catecholamine) activity on $\beta$ receptors. $\beta_{1}$-ISA leads to the absence of negative chronotropy in the resting state. On a renal level it leads to decreased suppression of renin release. $\beta_{2}$-ISA induces vasodilation of peripheral vessels. ${ }^{5}$

First-generation $\beta$-blockers are non-selective agents, the prototype being propranolol. Second-generation agents bind more selectively to $\beta_{1}$ receptors. Third-generation or vasodilating $\beta$-blockers are structurally different and have $a_{1}$-blocking, $\beta_{2}$-stimulating, NO-generating, antioxidant and anti-inflammatory properties. ${ }^{5}$

\section{Pharmacology - stereochemistry}

$\beta$-blockers contain one or several stereogenic centres in their structure rotating the plane of polarisation of linearly 


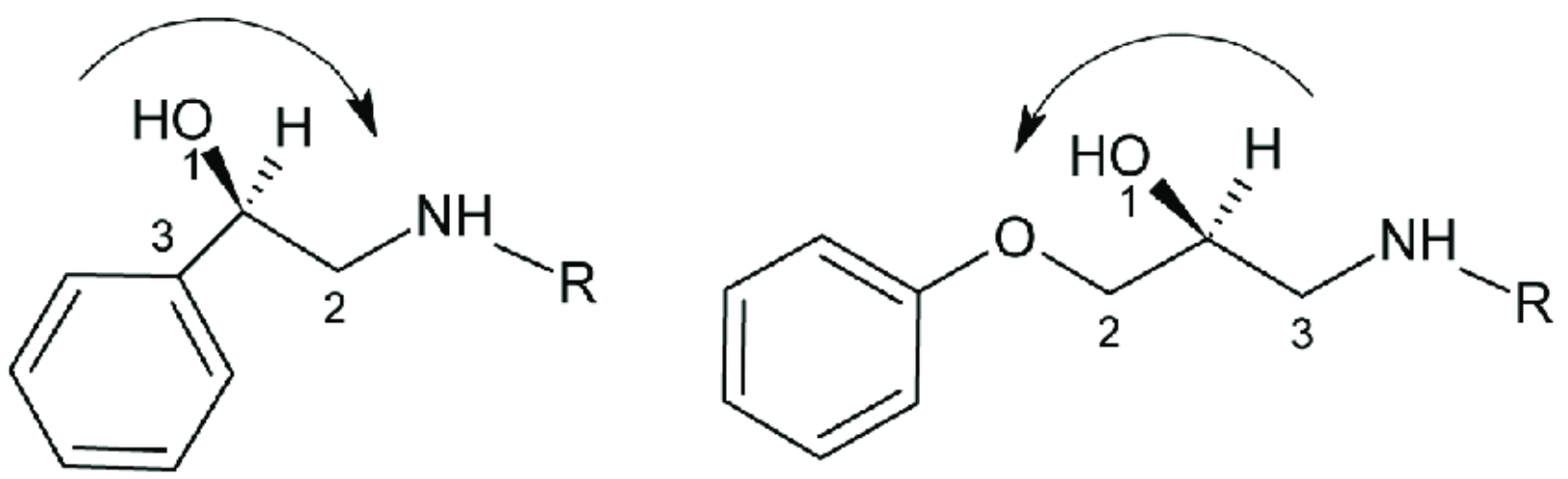

Figure 1: Structure and stereochemistry of aryl aminoethanols (left) and aryloxyaminopropanols (right) ${ }^{7}$

polarised light either to the left $(-)$ or to the right $(+) .{ }^{7}$ Older literature used the terms laevo (I) and dextro (d) to describe the direction of rotation of polarised light. Agents can be classified as aryl aminoethanols or aryloxyaminopropanols (Figure 1) according to their chemical structure. In both groups the more active isomers pertaining to their $\beta$-adrenolytic activity are the $(-)$-isomers which can be attributed the (R)-configuration for the aryl aminoethanol group and (S) for the aryloxyaminopropanol group.?

In practice, $\beta$-blockers are mostly used as a racemic mixture, except atenolol, penbutolol and timolol which are used as pure enantiomers.

\section{Classification}

$\beta$-blockers are usually categorised into the groups shown in Table I.

\section{Indications}

Some uses depending on individual agents include: ${ }^{1,6,9}$

- Ischaemic heart disease - including angina and acute coronary syndromes

- Arrhythmias
- Congestive heart failure

- Hypertension

- Hyperthyroidism

- Glaucoma (eye drops)

- Hypertrophic obstructive cardiomyopathy

- Anxiety disorders

- Migraine prophylaxis

- Essential tremor

\section{Pharmacokinetics}

Some general pharmacokinetics of $\beta$-blockers include: ${ }^{1,6}$

- Weak bases (pKa 9.5)

- High volume of distribution

- Bind to albumin and $a_{1}$-glycoprotein

- Interpatient variability occurs secondary to:

- differences in basal sympathetic tone,

- flat dose response curves,

- impact of active metabolites, and

- genetic differences in $\beta$-adrenergic receptors.

Commonly used agents are summarised in Table II.

Table I: $\beta$-blocker classification ${ }^{5-9}$

\begin{tabular}{lll}
\hline B-blocker & Features & Examples \\
\hline Cardioselective $(\neq I S A)$ & Block $\beta_{1}\left(\beta_{2}\right.$ only at high dose) & Atenolol, bisoprolol, esmolol, metoprolol \\
Cardioselective $(\sqrt{ } \mid S A)$ & $\beta$-adrenolytic with vasodilatant effect & Acebutolol \\
Non-selective $(\neq I S A)$ & $\beta_{1}$ and $\beta_{2}$ & Propranolol, sotalol, timolol \\
Non-selective $(\sqrt{ } \mid S A)$ & Partial agonist activity & Pindolol, bopindolol \\
a- and $\beta$-blocker & & Carvedilol, labetalol \\
Lipophilic & Hepatic metabolism, penetrate BBB & \\
Hydrophilic & Renal elimination, binds plasma proteins & \\
\hline
\end{tabular}

Table II: Pharmacokinetic properties of $\beta$-blockers ${ }^{1,6,8,9}$

\begin{tabular}{|c|c|c|c|c|c|c|}
\hline \multirow{2}{*}{$\begin{array}{l}\text { Agent } \\
\text { Propranolol }\end{array}$} & \multicolumn{2}{|c|}{ Oral absorption and bioavailability } & \multirow{2}{*}{$\frac{\text { Protein binding }}{90 \%}$} & \multirow{2}{*}{$\frac{\text { Lipid solubility }}{\text { High }}$} & \multicolumn{2}{|c|}{ Elimination half-life and clearance } \\
\hline & $100 \%$ & $30 \%$ & & & 3-4 hours & Hepatic \\
\hline Atenolol & $40-60 \%$ & $40 \%$ & $5 \%$ & Low & 6-7 hours & Renal \\
\hline Carvedilol & & $25-35 \%$ & $95 \%$ & Moderate & $7-10$ hours & Hepatic \\
\hline Metoprolol & $>95 \%$ & $50 \%$ & $10 \%$ & Moderate & 3-4 hours & Hepatic \\
\hline Labetalol & $>90 \%$ & $30-40 \%$ & $50-90 \%$ & Moderate & 4-8 hours & Hepatic \\
\hline Esmolol & \multicolumn{2}{|c|}{$\mathrm{N} / \mathrm{A}$} & $55 \%$ & Low & $9 \min$ & RBC esterase \\
\hline
\end{tabular}




\section{Side effects ${ }^{1,5,6,8}$}

Cardiovascular: Negative inotropy and chronotropy. Slowing of impulses through AV node. Decreased phase 4 depolarisation. Exercise intolerance. Cardiac failure in previously compensated patient.

Respiratory: Bronchoconstriction if non-selective agents are used especially in patients with obstructive airway disease. Selective $\beta_{1}$-agents unlikely to increase airway resistance.

Metabolic: Hyperglycaemia and worsening lipid parameters that are dose and agent dependant. Proposed mechanisms for these metabolic effects include: ${ }^{8}$

- Insulin release from the pancreas inhibited

- Resistance to insulin

- Insulin receptor downregulation

- Increased weight

- Total energy expenditure reduction

- Resting energy expenditure reduction

- Reduced thermic effect of foods

- Non-exercise thermogenesis reduction

- Inhibition of lipolysis

- Lipoprotein lipase enzyme activity reduction

- Endothelial dysfunction

Hyperkalaemia - $\beta$-blockers inhibit uptake of potassium into skeletal muscle cells.

Central nervous system: Lipid-soluble drugs will cross bloodbrain barrier leading to fatigue and lethargy. Vivid dreams are frequent.

Fetus: Can cross the placenta and cause bradycardia, hypotension and hypoglycaemia in the newborn. Excreted in breast milk.

Interaction with anaesthesia: Additive cardiovascular depression is not significant if isoflurane, sevoflurane or desflurane is used. Cardiovascular responses to high doses of fentanyl not altered with $\beta$-blockers.

\section{Overdose}

Features associated with a $\beta$-blocker overdose include: ${ }^{1}$

- Bradycardia, hypotension, low cardiac output and cardiogenic shock.
- Bronchospasm and depression of ventilation.

- Seizures and prolonged intraventricular cardiac conduction.

- Hypoglycaemia.

Management includes agents that will increase heart rate and contractility without activating the adrenergic receptors. These include atropine, glucagon, phosphodiesterase inhibitors and calcium chloride (offset excessive cardiovascular depression). Pacing can also be employed and $\mathrm{MgSO}^{4}$ administered if torsades is present. ${ }^{1,6}$

\section{Conflict of interest}

The author declares no conflict of interest.

\section{Funding source}

None.

ORCID

L Gilliland iD https://orcid.org/0000-0003-2974-4209

References

1. Stoelting RK, Hiller SC. Pharmacology \& physiology in anesthetic practice. 4th ed. Lippincott Williams \& Wilkins; 2006. p. 321-37.

2. Jørgensen ME, Andersson C, Venkatesan S, Sanders RD. Beta-blockers in noncardiac surgery: did observational studies put us back on safe ground? $\mathrm{Br}$ Anaesth. 2018;121:16-25. https://doi.org/10.1016/j.bja.2018.02.004.

3. Wijeysundera DN, Duncan D, Nkonde-Price C, et al. Perioperative beta blockade in noncardiac surgery: a systematic review for the 2014 ACC/AHA guideline on perioperative cardiovascular evaluation and management of patients undergoing noncardiac surgery: a report of the American College of Cardiology/ American Heart Association Task Force on Practice Guidelines. Circulation 2014:130:2246-64. https://doi.org/10.1161/CIR.0000000000000104.

4. Fleisher LA, Fleischmann KE, Auerbach AD, et al. 2014 ACC/AHA guideline on perioperative cardiovascular evaluation and management of patients undergoing noncardiac surgery: executive summary: a report of the American College of Cardiology/American Heart Association Task Force on Practice Guidelines. Circulation. 2014;130:2215-45. https://doi.org/10.1161/ CIR.0000000000000105.

5. Gorre F, Vandekerckhove H. Beta-blockers: focus on mechanism of action Which beta-blocker, when and why? Acta Cardiol. 2010;65:565-70. https://doi org/10.1080/ac.65.5.2056244.

6. Nienaber LN, Biccard BM. Autonomic nervous system. In: Milner A, Welch E. Applied pharmacology in anaesthesiology and critical care. 1st ed. Centurion: Medpharm Publications; 2012. p. 145-96

7. Cizmáriková R, Habala L, Valentová J, Markuliak M. Survey of pharmacological activity and pharmacokinetics of selected $\beta$-adrenergic blockers in regard to their stereochemistry. Applied Sciences. 2019:9:625. https://doi.org/10.3390/ app9040625.

8. Ripley TL, Saseen JJ. $\beta$-Blockers: a review of their pharmacological and physiological diversity in hypertension. Ann Pharmacother. 2014;48:723-33. https://doi.org/10.1177/1060028013519591.

9. Kirsch D. The pharmacology of beta-blockers and statins. Part I Anaesthesia Refresher Course. University of Cape Town; 2009. 